European

Neurology
Eur Neurol 2006;55:111-112

DOI: $10.1159 / 000092788$
Received: January 20, 2006

Accepted: January 20, 2006

Published online: April 21, 2006

\title{
Reply to the Paper by Wiendl et al.: Diffusion Abnormality in Baló's Concentric Sclerosis: Clues for the Pathogenesis
}

\author{
David J. Anschel
}

Stony Brook Univesity School of Medicine, Department of Neurology, Stony Brook, N.Y., USA

Dear Sir,

Thank you very much for recently publishing the article 'Diffusion Abnormality in Baló's Concentric Sclerosis: Clues for the Pathogenesis' by Wiendl et al. [1]. I would like to share with your readers a recent case with clinical history, laboratory testing, and MRI findings consistent with Baló's concentric sclerosis (BCS) and normal diffusion-weighted imaging (DWI).

A 32-year-old generally healthy man of Bolivian descent, who was employed in light indoor construction work, had awoken 1 week prior to admission with a tingling sensation in his left neck. Over the course of the next 1-2 days it progressed to involve his entire left body and extremities from the neck down. He then gradually developed clumsiness and weakness of the left hand as well as difficulty walking (in retrospect he said that his sister had mentioned that he was not walking correctly for 2-3 weeks, but the patient himself felt normal). He tried some sort of herbal treatment for 2 days with no effect and then came in to the emergency room.

Exam findings included left upper and bilateral $(\mathrm{L}>\mathrm{R})$ lower extremity dysmetria. There was an upper motor neuron pattern of weakness in the left upper and lower extremity (distal $>$ proximal).

Relevant laboratory results included positive oligoclonal bands, HIV (-), normal serum/CSF IgG index, myelin basic protein elevated to 9.40 (normal 0.07-4.1), cerebrospinal fluid - 1 WBC, 1 RBC, protein 31.4, glucose 62 .
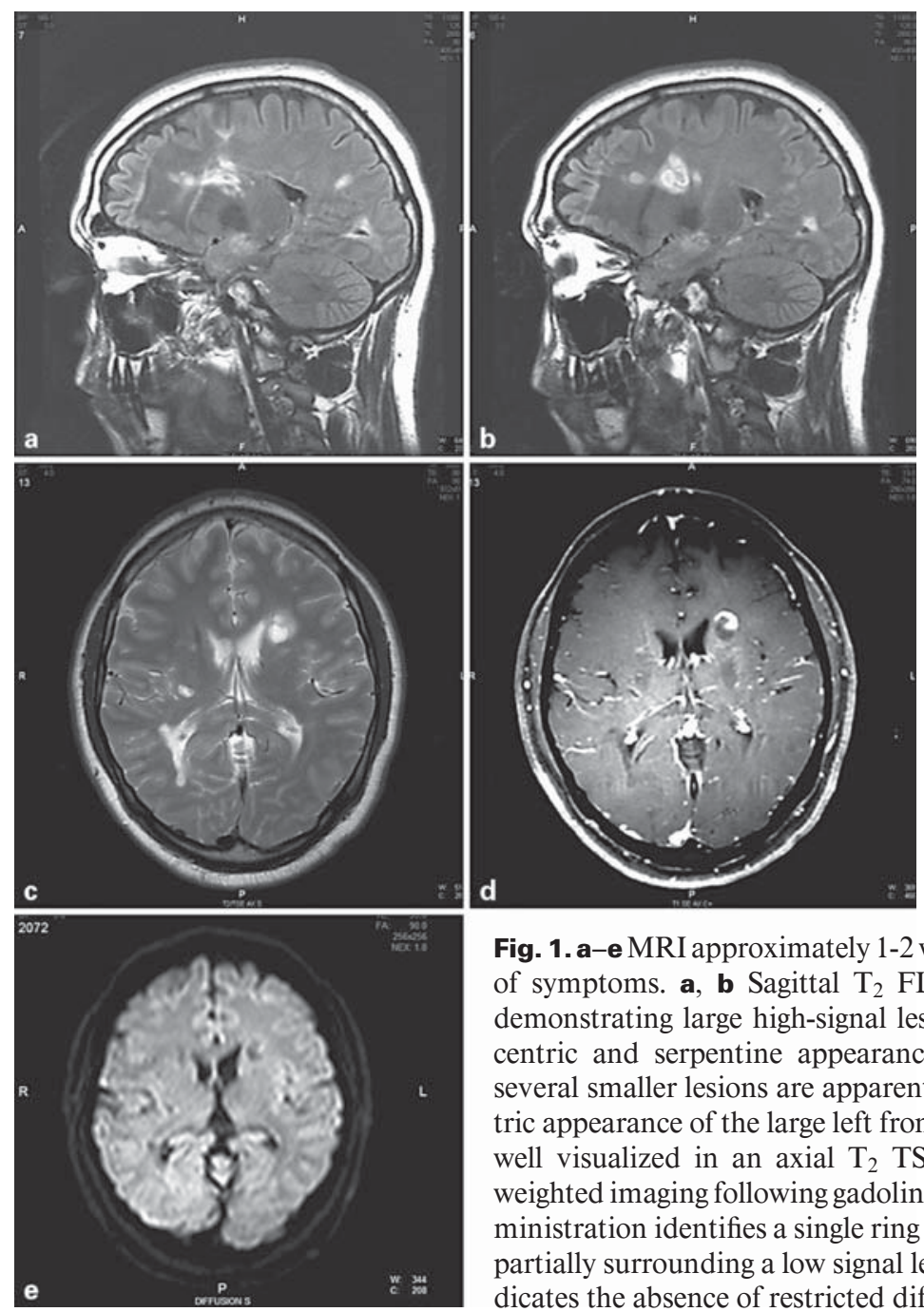

Fig. 1. a-e MRI approximately 1-2 weeks after onset of symptoms. a, b Sagittal $\mathrm{T}_{2}$ FLAIR sequences demonstrating large high-signal lesion with a concentric and serpentine appearance. Additionally, several smaller lesions are apparent. c The concentric appearance of the large left frontal lesion is also well visualized in an axial $\mathrm{T}_{2}$ TSE image. d $\mathrm{T}_{1}$ weighted imaging following gadolinium contrast administration identifies a single ring of enhancement partially surrounding a low signal lesion. e DWI indicates the absence of restricted diffusion.

\section{KARGER}

Fax +4161306 1234 E-Mail karger@karger.ch www.karger.com
David J. Anschel, MD, Department of Neurology

Health Sciences Center, T-12, 020

Stony Brook, NY 11794-8121 (USA)

Tel. +1 6314448118 , Fax +1 6314441474

E-Maildanschel@bnl.gov 
The MRI (Philips 3T) revealed multiple lesions within both the brain and the spine consistent with demyelination. Two of the brain lesions had a lamellar appearance. One of these lesions met the proposed MRI criteria for BCS [2]. $\mathrm{T}_{2}$-weighted imaging suggested separate concentric zones of demyelination and $\mathrm{T}_{1}$-weighted imaging following gadolinium contrast administration depicted a separate ring of enhancement. DWI did not indicate restricted diffusion in the corresponding area (fig. 1).

Since some cases of BCS appear to have DWI abnormalities while others do not, it is possible that more than one pathological process may underlie the abnormalities seen on other MRI sequences, and traditional histopathology. This suggests that the finding of concentric sclerosis as im- aged by MRI or using traditional histopathology is actually a somewhat non-specific sign, rather than diagnostic of a specific disease. This is supported by the clinical finding that concentric sclerosis has been associated with a wide range of outcomes, including rapidly progressive demyelination, self-limited monophasic disease, and typical relapsing remitting multiple sclerosis [3, 4]. Another possibility is that disease outcome is primarily determined by the underlying cause of demyelination and the formation of concentric rings is an individual response which is determined by genetic factors. This later possibility is supported by the fact that a recent study has indicated that layers of preserved myelin in between lesions contain specific neuroprotective peptides [5].

\section{References}

1 Wiendl H, Weissert R, Herrlinger U, Krapf H, Küker W: Diffusion abnormality in Baló's concentric sclerosis: clues for the pathogenesis. Eur Neurol 2005;53:42-44.

2 Caracciolo JT, Murtagh RD, Rojiani AM, Murtagh FR: Pathognomonic MR imaging findings in Baló concentric sclerosis. AJNR Am J Neuroradiol 2001;22:292-293.

3 Kastrup O, Stude P, Limmroth V: Baló's concentric sclerosis. Evolution of active demyelination demonstrated by serial contrast-enhanced MRI. J Neurol 2002;249:811-814.

4 Karaarslan E, Altintas A, Senol U, Yeni N, Dincer A, Bayindir C, et al: Baló's concentric sclerosis: clinical and radiologic features of five cases. AJNR Am J Neuroradiol 2001;22:13621367.

5 Stadelmann C, Ludwin S, Tabira T, Guseo A, Lucchinetti CF, Leel-Ö L, Ordinario AT, Bruck W, Lassmann H: Tissue preconditioning may explain concentric lesions in Baló's type of multiple sclerosis. Brain 2005;128: 979-987. 